\title{
Psychosocial Factors at Work and Occupational Stress in Gas Station Attendants in Ecuador
}

\author{
Guido Germán Albán-Pérez ${ }^{1}$ Manuel Pando-Moreno², Francisco Laca-Arocena ${ }^{3}$, \\ Cecilia Colunga-Rodríguez ${ }^{4}$, Ángel María Verdesoto-Galéas ${ }^{1}$, \\ Luis Edmundo Sarabia-López ${ }^{1}$, Marco Marcelo León-Navarrete ${ }^{1}$ \\ ${ }^{1}$ Facultad de Ciencias Psicológicas, Universidad Central del Ecuador, Quito, Ecuador \\ ${ }^{2}$ Centro Universitario de Ciencias de la Salud, Universidad de Guadalajara, Guadalajara, México \\ ${ }^{3}$ Facultad de Psicología, Universidad de Colima, Colima, México \\ ${ }^{4}$ Instituto Mexicano del Seguro Social y Universidad de Guadalajara, Guadalajara, México \\ Email: guidoalban62@hotmail.com
}

How to cite this paper: Albán-Pérez, G. G., Pando-Moreno, M., Laca-Arocena, F., Colunga-Rodríguez, C., Verdesoto-Galéas, Á. M., Sarabia-López, L. E., \& León-Navarrete, M. M. (2017). Psychosocial Factors at Work and Occupational Stress in Gas Station Attendants in Ecuador. Psychology, 8, 2215-2225. https://doi.org/10.4236/psych.2017.813141

Received: October 19, 2017

Accepted: November 26, 2017

Published: November 29, 2017

Copyright $\odot 2017$ by authors and Scientific Research Publishing Inc. This work is licensed under the Creative Commons Attribution International License (CC BY 4.0).

http://creativecommons.org/licenses/by/4.0/

\begin{abstract}
The aim was to determine the association between the psychosocial factors at work and occupational stress in gas station attendants in Ecuador. A transversal study was conducted, including 146 dispatchers of petroleum-derived products. The participants answer a sociodemographic data, the Instrumento de Factores Psicosociales en el Trabajo (Survey of Psychosocial Factors at Work) and the Cuestionario de Evaluación del Estrés (Stress Evaluation Survey). The mean age was of 30.05 years $(S D=8.31)$, being $67.7 \%$ males. The results indicated that the participants perceived a high exposition to the psychosocial factors at work Social interaction (61\%), and Organizational aspects and Performance remuneration (47.3\%). About the occupational stress, we observed high levels of psychoemotional symptoms $(88.4 \%)$, followed by those regarding social behavior (74\%). When analyzing for the associations between psychosocial factors at occupational stress, we observed several significant correlations, finding that the factors Content and characteristics ot the task $(p<0.005)$ and Job role and carrier development $(p<0.005)$ presented the higher number of associations with the presence of occupational stress symptoms. We conclude that, the gas station attendants perceive a high exposition to different psychosocial factors at work, which are associated with the presence of high levels of occupational stress, being important to develop further research and interventions that promote the health and wellbeing of this group.
\end{abstract}

\section{Keywords}

Psychosocial Factors, Occupational Stress, Service Stations, 
Petroleum Derived Products, Occupational Health

\section{Introduction}

In Ecuador, as in many Latin-American countries, the service stations of petroleum derived products (gasoline and diesel), are commonly operated by staff directly hired by fuel companies. This group of workers has as main activities, the reception and dispatching of fuels, along with the attention to clients, working under conditions that represent a risk for health in different areas. One of the most explore topics with this population are the chemical risks present in their work conditions. Resent research findings indicate that gas station attendants have a significant exposure to gases such as benzene, which associates with myelotoxicity, the main cause of hematologic disorders such as aplastic anemia, myelodysplastic syndrome and myeloid acute leukemia (Santiago et al, 2014; Mitri, Almeida, Barros, Medeiros, Costa, \& de Novaes, 2015). In addition, this type of exposure associates with respiratory disorders and cognitive impairment (Angamarca, 2014; Pérez-Zamora, Ostrosky-Shejet, \& López-Portillo, 2016). Besides the chemical risks, other work conditions can be categorized as risks for the health, such as fires, elevated noise, vibrations and the long-standing time required for this job (Valdivieso, 2015). Although the attention has been given mainly to the chemical and physical risks, this group of workers is also exposed to psychosocial risks at work, considering they interact directly with the gas services users, being in charge for the safety of the operation.

The psychosocial factors present in the working context can be of different nature, comprehending aspects related to the characteristics of the task, the job organization and the time destine to work (Gil-Monte, 2012). These factors become a risk when they are present in certain conditions of intensity and frequency, generating a stress response, which can be mediated by the individual accordingly to its coping skills. In this sense, the psychosocial risk factors art work is defined as the result of the interaction between the job characteristics, the environment and the work conditions, whit the worker skills, needs, culture and personal situation (ILO, 1984). We can understand them as work conditions that, when they overload the worker coping skills, begin to be perceived negatively, acquiring the potential to generate stress and other health and safety problems (Marcilla, 2010; Vieco \& Avello, 2014).

The service station attendants work under conditions that could represent psychosocial risk factors, such as the interaction with the customers and the increase of the job demands, derived from the constant market competition between fuel companies. This last factor favors a raise in the worker responsibilities, besides adding a constant change in the work conditions, situation that implies new workloads for the individual. As mentioned before, when we have an unbalance between the psychosocial factors present at work and the worker 
skills, it is easy to generate stress responses, one of the central topics when we talk about occupational health.

The stress, from a general approach, is defined as a physiologic and psychologic response against an external situation that is perceived as excessive, unpleasant or threatening by the subject (Lazarus, 1999). This adaptation response is mediated by the personal characteristics of the individual, originating different chemical changes in the body, which influence mental and physiologic processes (Durán, 2010; Lazarus \& Folkman, 1984). Authors such as Korman (1974), mention that each person has an optimal level of stress, which allows to perform positively in a task, working as a motivator. However, when the stress levels increase, there are several responses that can be triggered, affecting the subject negatively. The occupational stress generates when the work conditions become psychosocial risk factors that overload the individual coping skills, promoting stress responses manifested by physical and emotional alterations such as anxiety, irritability, sadness-depression, among others. Other important stress symptoms are the physical exhaustion and the performance decrease, observing that, if the stress is too intense and it is present for a long time, it is possible to originate physical and mental disorders (Cano, 2011). Likewise, in the work environments, the stress is associated to personal absence and work accidents (Gamero, 2010). The stress can be seen as something unavoidable in the work places. Whatever we look, we can find multiple potential sources of stress that can affect the wellbeing and endanger the mental and physical health (Weiss 2004). According to a study developed by the polling company Regus, $75 \%$ of the people that feel stress in Mexico, referred its origin to the work environment, percentage that decreases to $73 \%$ in China and 59\% for the United States (Senado de la República, 2016).

The association between psychosocial risk factors and occupational stress is a topic studied in different populations around the world, reporting that the increase of the frequency and intensity of these risk factors, is usually accompanied by an increase in the occupational stress levels, as well as in the negative consequences for the health (Tuvesson \& Eklund, 2014; Gerr et al, 2014; Rahman, Abdul-Mumin, \& Lin, 2016). However, only few researches have approached the psychosocial area with the service station attendants, a group that, as mentioned before, performs under conditions that can be identify as important psychosocial risk factors, besides the chemical and physical factors broadly studied before. Considering this, the aim of this study was to determine the association between the psychosocial factors at work and occupational stress in gas station attendants in Ecuador.

\section{Methodology}

\subsection{Participants}

The sample included 146 attendants of petroleum-derived service stations from 
one company that provides services for all Ecuador. We used a census method, including all the company's operative employees in charge of receiving and dispatching fuels. The participants work in service stations distributed along the Cost, Mountain range and East part of Ecuador, having different weather, social and contextual conditions.

\subsection{Instruments}

\subsubsection{Sociodemographic Data}

The participants answer a sociodemographic data sheet, which included the variables: gender, age, educational level and job seniority. The gender was registered as 1) male and 2) female. The age was captured in years gather at the moment of the data collection. The educational level was registered in 1) elementary school, 2) middle school, 3) high school, 4) college and 5) postgraduate. The job seniority was captured in number of years working in the same work position.

\subsubsection{Psychosocial Risk Factors at Work}

We used the Cuestionario Factores Psicosociales en el Trabajo" (Psychosocial factors at work Survey), adapted to Peruvian population (Pando, Varillas, Aranda, \& Elizalde, 2016). The survey evaluates the frequency in which the psychosocial factors are present in the work environment, including 46 items $(\alpha=0.9)$. The items are divided into seven dimensions: workplace conditions (9), workload (5), content and characteristics of the task (7), work demands (7), professional role and career development (6), social interaction and organizational aspects (9), and performance remuneration (3). The answer options are in a five point Likert scale, going from never to always. The total scores for each dimension are classified in three levels: low, medium and high, stablishing a risk level perceived by the individual (Pando, Varillas, Aranda, \& Elizalde, 2016).

\subsubsection{Occupational Stress}

We applied the Cuestionario de Evaluación del Estrés (Stress Evaluation Survey), in its third version, validated in Colombia $(\alpha=0.88)$. This instrument evaluates the frequency in which the person experience symptoms relating to stress in different areas. It includes 31 items, divided in four dimensions: Physiological symptoms (8), Social behavioral symptoms (4), Intellectual-work symptoms (10) and Psychoemotional symptoms (9). The answer options are presented in a four point Likert scale, going from always to never.

We used the evaluation scale applied to operational personal, aimed for people working in positions that do not require special knowledge, usually following direct instructions from a superior. This scale allows to categorize the survey's total scores into five levels, according to the frequency of the symptoms: very low, low, medium, high and very high (Villalobos, 2004).

\subsection{Data Collection}

Initially, we performed an informative session with administrative directors of 
the petroleum-derive products company selected for the development of this research, in which, we explained the study's aims and procedures. Once the directors agreed to participate in the research, we conducted a second session with all the service station attendants, proceeding to explain the characteristics of the study and its ethical considerations. In the same meeting, the individuals that agreed to participate in the research signed an informed consent form. A second session was schedule, in which we applied the selected surveys, which were answered in in a self-report format, during regular work hours.

\subsection{Data Analysis}

We develop a data base in Excel 2010, which was analyzed using SPSS version 23. Descriptive statistics (frequencies, percentages and central tendency measurements) were applied to the sociodemographic data, the results from the Escala de Factores Psicosociales en el Trabajo (Psychosocial factors at work Survey) and from the Cuestionario de Evaluación del Estrés (Stress Evaluation Survey). For the analysis of the association between the study variables, we used Chi Square, proceeding to apply Spearman's Correlation Coefficient in order to determine the directionality of the correlation. In both statistics, we considered a significant association when $p<0.05$.

\section{Results}

The final sample was constituted by 146 attendants of service stations. The participant were $67.7 \%$ males, with a mean age of 30.05 years $(S D=8.31)$, minimum of 18 and maximum of 63 years. The distribution of the educational level of the participants is presented in Table 1. Regarding the job seniority, we found a mean of 2.85 years $(S D=3.08)$, with a minimum of one and a maximum of 20 years in the same job position.

\subsection{Psychosocial Factors at Work}

The Escala de Factores Psicosociales en el Trabajo (Psychosocial factors at work Survey) categorizes the dimensions' total scores in three levels, according to the degree of exposure perceived to the psychosocial factor evaluated. Table 2 presents the results obtained from this survey, finding that the factor "Social Interaction and organizational aspects" presented the higher percentages of per-

Table 1. Educational level of the participants.

\begin{tabular}{ccc}
\hline Educational level & $\mathrm{n}$ & $\%$ \\
\hline Elementary school & 13 & 8.9 \\
Middle school & 124 & 84.9 \\
High school & - & - \\
College & 9 & 6.2 \\
Postgraduate & - & - \\
\hline
\end{tabular}

Note: $\mathrm{N}=146, \mathrm{n}=$ frequency. 
Table 2. Level of perceived exposure to Psychosocial Factors at Work.

\begin{tabular}{cccccccc}
\hline & \multicolumn{5}{c}{ Level of percieved exposure } \\
\cline { 2 - 7 } Psychosocial Factors at Work & \multicolumn{2}{c}{ Low } & \multicolumn{2}{c}{ Medium } & \multicolumn{2}{c}{ High } \\
\cline { 2 - 8 } & $\mathrm{n}$ & $\%$ & $\mathrm{n}$ & $\%$ & $\mathrm{n}$ & $\%$ \\
\hline Workplace conditions & 10 & 6.8 & 105 & 71.9 & 31 & 21.2 \\
Workload & 18 & 12.3 & 115 & 78.8 & 13 & 8.9 \\
Content and characteristics of the task & 7 & 4.8 & 97 & 66.4 & 42 & 28.8 \\
Work demands & 47 & 32.2 & 81 & 55.5 & 18 & 12.3 \\
Professional role and career development & 21 & 16.4 & 86 & 58.9 & 36 & 24.7 \\
Social interaction and organizational aspects & 2 & 1.3 & 55 & 37.7 & 89 & 61 \\
Performance remuneration & 13 & 8.9 & 64 & 43.8 & 69 & 47.3 \\
\hline
\end{tabular}

Note: $\mathrm{N}=146, \mathrm{n}=$ frequency.

Table 3. Characterization of the work stress levels perceived.

\begin{tabular}{cccccccccccc}
\hline & \multicolumn{2}{c}{ Very low } & \multicolumn{2}{c}{ Low } & \multicolumn{2}{c}{ Medium } & \multicolumn{2}{c}{ High } & \multicolumn{2}{c}{ Very high } \\
\cline { 2 - 11 } Stress symptoms & $\mathrm{n}$ & $\%$ & $\mathrm{n}$ & $\%$ & $\mathrm{n}$ & $\%$ & $\mathrm{n}$ & $\%$ & $\mathrm{n}$ & $\%$ \\
\hline Physiological & 44 & 30.1 & 19 & 13 & 14 & 9.6 & 35 & 24 & 34 & 23.3 \\
Social behavioral & 1 & 0.7 & 3 & 2.1 & 6 & 4.1 & 28 & 19.2 & 108 & 74 \\
Intellectual-work & 9 & 6.2 & 29 & 19.9 & 33 & 22.6 & 45 & 30.8 & 30 & 20.5 \\
Psychoemotional & - & - & - & - & 1 & 0.7 & 16 & 11 & 129 & 88.4 \\
\hline
\end{tabular}

Note: $\mathrm{N}=146, \mathrm{n}=$ frequency.

ceived exposure, followed by the factor "Performance remuneration".

\subsection{Occupational Stress}

Regarding occupational stress, the survey results provide data about the frequency in which the participants experience different symptoms related to this type of stress. We found that psychoemotional symptoms were the most frequently reported by the participants, followed by the physiological symptoms (Table 3).

\subsection{Association between the Psychosocial Factors at Work and Occupational Stress}

We used Chi square to determine the association between the study variables, finding that the dimension "Work demands" did not associated with any occupational stress symptoms. The dimensions "Workplace conditions" and "Workload" only associated with physiological $(p<0.05)$ and Intellectual-work $(p<$ $0.005)$ symptoms, respectively. The factors with a higher number of associations were "Content and characteristics of the task" and "Professional role and career development" (Table 4).

Later, the variables that presented a significant association were submitted to a 
Table 4. Associations between psychosocial work factors and work stress using Chi square.

\begin{tabular}{ccccc}
\hline Psychosocial Work Factors & $\begin{array}{c}\text { Physiological } \\
\text { symptoms }\end{array}$ & $\begin{array}{c}\text { Social behavior } \\
\text { symptoms }\end{array}$ & $\begin{array}{c}\text { Intellectual-work } \\
\text { symptoms }\end{array}$ & $\begin{array}{c}\text { Phsycoemotional } \\
\text { symptoms }\end{array}$ \\
\hline Workplace conditions & 0.046 & 0.219 & 0.213 & 0.111 \\
$\quad$ Workload & 0.075 & 0.691 & 0.008 & 0.375 \\
$\begin{array}{c}\text { Content and characteristics } \\
\text { of the task }\end{array}$ & 0.000 & 0.000 & 0.000 & 0.050 \\
$\quad \begin{array}{c}\text { Work demands } \\
\text { Professional role and } \\
\text { career development }\end{array}$ & 0.465 & 0.632 & 0.137 & 0.863 \\
$\begin{array}{c}\text { Social interaction and } \\
\text { organizational aspects }\end{array}$ & 0.000 & 0.002 & 0.000 & 0.032 \\
$\begin{array}{c}\text { Performance remuneration } \\
\text { N }\end{array}$ & 0.001 & 0.012 & 0.001 & 0.085 \\
\hline
\end{tabular}

Note: The table presents $\mathrm{P}$ values, considering significant the associations with a $p<0.05$.

Table 5. Correlations coefficients for the associations between psychosocial work factors and occupational stress.

\begin{tabular}{|c|c|c|c|c|c|c|c|c|}
\hline \multirow{2}{*}{ Psychosocial Work Factors } & \multicolumn{2}{|c|}{$\begin{array}{l}\text { Physiological } \\
\text { symptoms }\end{array}$} & \multicolumn{2}{|c|}{$\begin{array}{l}\text { Social behavior } \\
\text { symptoms }\end{array}$} & \multicolumn{2}{|c|}{$\begin{array}{l}\text { Intellectual-work } \\
\text { symptoms }\end{array}$} & \multicolumn{2}{|c|}{$\begin{array}{c}\text { Phsycoemotional } \\
\text { symptoms }\end{array}$} \\
\hline & $\mathrm{r}^{2}$ & $\mathrm{p}$ & $\mathrm{r}^{2}$ & $\mathrm{p}$ & $r^{2}$ & $\mathrm{p}$ & $\mathrm{r}^{2}$ & $\mathrm{p}$ \\
\hline Workplace conditions & NS & NS & NS & NS & NS & NS & NS & NS \\
\hline Workload & NS & NS & NS & NS & 0.325 & 0.000 & NS & NS \\
\hline $\begin{array}{c}\text { Content and characteristics } \\
\text { of the task }\end{array}$ & 0.456 & 0.000 & 0.337 & 0.000 & 0.493 & 0.000 & 0.193 & 0.020 \\
\hline Work demands & 0.426 & 0.000 & 0.371 & 0.000 & 0.498 & 0.000 & 0.209 & 0.011 \\
\hline $\begin{array}{c}\text { Professional role and career } \\
\text { development }\end{array}$ & 0.487 & 0.000 & 0.457 & 0.000 & 0.516 & 0.000 & NS & NS \\
\hline $\begin{array}{l}\text { Social interaction and } \\
\text { organizational aspects }\end{array}$ & 0.353 & 0.000 & 0.300 & 0.000 & 0.413 & 0.000 & NS & NS \\
\hline
\end{tabular}

Note: We considered significant the associations with a $p<0.05$.

correlation analysis using Spearman's Coefficient. The dimension "Work demands" was eliminated from the analysis because it did not present significant associations. The results are presented in Table 5, all the correlations maintained a positive directionality.

\section{Discussion}

The attendants from the service stations of petroleum-derived products are exposed to different type of risks, being one of them, the psychosocial factors present in their work environment. This type of factors represent relevant aspects of the work conditions because of its association with stress, a phenomenon that favors the appearance of physical and mental health problems. Despite the importance of this topic, there are only few researches approaching psy- 
chosocial aspects existing in the work conditions of this population. Considering this, the aim of this research was to determine the association between the psychosocial factors at work and occupational stress in gas station attendants in Ecuador.

Beginning to talk about the perception of psychosocial factors at work, we found that a high percentage of the participants considered to have a significant exposure to most of the dimensions included in the survey. Particularly, we observed considerable percentages of a "high" exposure to factors related to "Social interaction and organizational aspects" and "Performance remuneration". This results agree with the reported by other studies that point out that, the characteristics of the remuneration is one of the psychosocial factors usually perceived negatively by operational employees, associating with a dissatisfaction with the balance between the perceived effort destine to work and the reward received (Arenas \& Andrade, 2013). These findings needs to be resumed in future research focus in the development of preventive strategies, considering that the remunerations, the type of contract and the organizational support perceived by the company are elements that influence aspects such as Quality of Work Life (Uribe, Garrido, \& Rodríguez, 2011). Besides that, several research has point out that the perception of an unbalance between these work characteristics are psychosocial risk factors that promote the generation of other problems such as exhaustion and burnout.

Regarding the stress, we evaluated the presence of different symptoms related to occupational stress, finding a higher report for psychoemotional symptoms, with a percentage over $70 \%$ of the participants referring a "very high" frequency. This finding suggests that participants might be perceiving a significant presence of stress in their work activities, a relevant result considering the physical, emotional and social problems related to the elevated presence of occupational stress. Considering this, it is necessary to keep gathering information about this phenomenon and in this particular population, making possible to develop preventing and health promotion strategies.

Finally, we analyzed the association between psychosocial factors at work and occupational stress, aiming to identify work environment characteristics that might be favoring the presence of symptoms relating to stress. Interestingly, the psychosocial factors that presented a correlation with occupational stress symptoms were the "Content and characteristics of the task" and the "Professional role and career development", variables related not only with stress, but with more severe problems, such as burnout. Some authors point out that, the presence of psychosocial factors such as "Professional role and career development" quadruple the possibilities that the worker presents emotional exhaustion (Silva, Gutiérrez, Pando, \& Tuesca, 2014).

Likewise, we observed, that the factors "Social interaction and organizational aspects" and "Performance remuneration" appeared as variables associated to Physiological, Social-behavioral and Intellectual-work stress symptoms. As men- 
tioned before, the perception of a lack of support from the organization and the unbalance between the effort demanded from the job and the economical remuneration received, are factors that generate frustration and stress. This is an important topic because of its association with the generation of other problems, considering that, among other things, the perception of an unbalance in the effort-reward at work, doubles the possibility of experimenting emotional exhaustion (Silva, Gutiérrez, Pando, \& Tuesca, 2014). It is necessary to add that, besides the physical and emotional consequences of the occupational stress, a stressful worker tend to have lower motivation, and even to present, what the literature refers as "presentism". This phenomenon is defined as the individual that regularly attends work with the intention to provide the less effort possible, or that uses the work hours in other activities that perceives as more rewarding, aiming to balance the effort-reward relation (García, 2011; Janssens, Clays, De Clercq, De Bacquer, Casini, Kittel, \& Braeckman, 2016).

The results from this research provide elements that allow to better understand the reality of a group of workers about which, the scientific research is usually more focus in biological aspects, providing a broader perspective about the way the psychosocial factors are experience, and its impact in aspects such as occupational stress. Despite the relevance of our findings, this study has limitations that need to be taken into consideration. Regarding the population, although we included all the gas station attendants of one petroleum-derived company in Ecuador, it is necessary to increase the sample size and include participants from different organizations, in order to be able to generalize the results and make comparisons. Likewise, it is important to develop future studies that include administrative staff, making possible to compare results between different types of personal working in the same industry. Finally, we recommend to complete these research findings with other studies develop from different methodologies, with predictive levels of analysis, and that include other important variables approached from a positive perspective, such as work satisfaction, quality of work life, etcetera.

\section{Conclusion}

The main findings of this research are that, the gas station attendants in Ecuador perceived a high level of exposure to different psychosocial factors, related to organizational aspects and remuneration characteristics, which associates with the referral of high symptoms of occupational stress. These results are relevant because, we are observing that this group of workers is developing their job activities with high stress levels, which can decrease their performance at work and promote the generation of physical and mental health problems. Considering this, we conclude that this population is in risk for the development of important alterations that impact at different levels, being necessary to conduct future research that allows a better comprehension of the organizational and contextual variables influencing in the high levels of occupational stress. Aiming to develop 
intervention strategies focusing on the wellbeing of this population, which can be materialize into public policies that provide a frame for the establishment of better work conditions that can promote a more favorable work environment.

\section{Acknowledgements}

Thanks to the Consejo Nacional de Ciencia y Tecnología (National Council of Science and Technology CONACyT), for the support received through the $\mathrm{PhD}$ grant used for the development of this research.

\section{References}

Angamarca, E. (2014). Respiratory Alterations Caused by Inhalation of Air Contamined by Gas Fuels by Gas Stations Attendants in Loja City. Thesis for Obtaining Medical Degree. Loja: Universidad Nacional de Loja.

Arenas, F., \& Andrade, V. (2013). Psychosocial Risk Factors in a Food Industry in the City of Cali. Pensamiento Psicológico, 11, 99-113.

Cano, A. (2011). Anxiety, Stress, Negative Emotions and Health. Revista Crítica, 60, 968.

Durán, M. (2010). Psychological Wellbeing: Stress and Quality of Life in the Working Context. Revista Nacional de Administración, 1, 71-84.

Gamero, C. (2010). Assessing the Cost of Lost Working Days Associated with Job Stress: A Proposal for Spain. Estudios de Economía Aplicada, Sin mes, 1-20.

García, M. (2011). Multifactorial Problem of Presentism and Absenteeism Procrastination in Structures in Which the Worker Develops. Medicina y Seguridad en el Trabajo, 57, 111-120.

Gerr, F., Fethke, N. B., Anton, D., Merlino, L., Rosecrance, J., Marcus, M., \& Jones, M. P. (2014). A Prospective Study of Musculoskeletal Outcomes among Manufacturing Workers: Effects of Psychosocial Stress and Work Organization Factors. Human Factors, 56, 178-190.

Gil-Monte, P. (2012). Psychosocial Risks at Work and Occupational Health. La Revista Peruana de Medicina Experimental y Salud Pública, 29, 237-241.

http://www.scielo.org.pe/scielo.php?script=sci_arttext\&pid=S1726-46342012000200012 \&lng=es\&nrm=iso

International Labor Office (1984). Psychosocial Factors at Work: Recognition and Control. Occupational Safety and Health Series, Ginebra.

Janssens, H., Clays, E., De Clercq, B., De Bacquer, D., Casini, A., Kittel, F., \& Braeckman, L. (2016). Association between Psychosocial Characteristics of Work and Presenteeism: A Cross-Sectional Study. International Journal of Occupational Medicine and Environmental Health, 29, 331-344.

Korman, A. (1974). The Psychology of Motivation. Prentice Hall: New York.

Lazarus, R. S. (1999). Stress and Emotion: A New Synthesis. New York: Springer.

Lazarus, R. S., \& Folkmans, S. (1984). Stress, Appraisal and Coping. New York: Springer.

Marcilla, T. (2010). Los riesgos psicosociales. Dyna, 85, 167-174. https://doi.org/10.6036/2851

Mitri, S., Almeida, A., Barros, U., Medeiros, M., Costa, J., \& de Novaes, P. (2015). Metabolic Polymorphisms and Clinical Findings Related to Benzene Poisoning Detected in Exposed Brazilian Gas-Station Workers. International Journal of Environmental Research and Public Health, 12, 8434-8447. https://doi.org/10.3390/ijerph120708434 
Pando, M., Varillas, W., Aranda, C., \& Elizalde, F. (2016). Exploratory and Factorial Analysis of the "Questionnaire of Psychosocial Factors at Work" in Peru. Anales de la Facultad de Medicina, 77, 365-371.

Pérez, I., Ostrosky, F., \& López, A. (2016). Cognitive Disorders from Exposure to Industrial Solvents in Mexican Workers. Archivos en Medicina Familiar, 18, 31-40.

Rahman, H., Abdul-Mumin, K., \& Lin, N. (2016). A Study into Psychosocial Factors as Predictors of Work-Related Fatigue. British Journal of Nursing, 25, 757-763. https://doi.org/10.12968/bjon.2016.25.13.757

Santiago, F., Alves, G., Otero, U. B., Tabalipa, M. M., Scherrer, L. R., Kosyakova, N., Liehr, T. et al. (2014). Monitoring of Gas Station Attendants' Exposure to Benzene, Toluene, Xylene (BTX) using Three-Color Chromosome Painting. Molecular Cytogenetics, 7, 15. https://doi.org/10.1186/1755-8166-7-15

Senado de la República (2016). http://www.senado.gob.mx http://www.senado.gob.mx/index.php? watch=13\&mn=1\&id=2828\&lg=63\&anio=1

Silva, D., Gutiérrez, A., Pando, M., \& Tuesca, R. (2014). Relationship between Negatives Psychosocial Factors and Burnout Syndrome in Health Workers in Florence (Caquetá, Colombia). Salud Uninorte, 30, 52-62. https://doi.org/10.14482/sun.30.1.4314

Tuvesson, H., \& Eklund, M. (2014). Psychosocial Work Environment, Stress Factors and Individual Characteristics among Nursing Staff in Psychiatric In-Patient Care. International Journal of Environmental Research \& Public Health, 11, 1161-1175. https://doi.org/10.3390/ijerph110101161

Uribe, A., Garrido, J., \& Rodríguez, A. (2011). Influence of the Type of Contracting on the Quality of Working Life: Signs of the Organizational Capitalism (pp. 1-16). Revista Virtual Universidad Católica del Norte, Mayo-Agosto.

Valdivieso, J. (2015). Determination of the Risk of Fire in a Fuel Distribution Station (Masters Dissertation). University of San Francisco de Quito.

Vieco Gómez, G. F., \& Abello Llanos, R. (2014). Psychosocial Factors at Work, Stress and Morbidity around the World (pp. 354-385). Psicología desde el Caribe, Mayo-Agosto. https://doi.org/10.14482/psdc.31.2.5544

Villalobos, G. (2004). Epidemiological Surveillance of Psychosocial Factors: Conceptual and Valuating Approaches. Ciencia y Trabajo, 6, 197-201.

Weiss, B. (2004). Eliminating the Stress. Barcelona: Ediciones B. S.A. 